IZA DP No. 7892

The Impacts of Vocational Rehabilitation

Simen Markussen

Knut Røed

January 2014

Forschungsinstitut zur Zukunft der Arbeit Institute for the Study of Labor 


\title{
The Impacts of Vocational Rehabilitation
}

\author{
Simen Markussen \\ Ragnar Frisch Centre for Economic Research \\ Knut Røed \\ Ragnar Frisch Centre for Economic Research \\ and IZA
}

Discussion Paper No. 7892

January 2014

IZA

P.O. Box 7240

53072 Bonn

Germany

Phone: +49-228-3894-0

Fax: +49-228-3894-180

E-mail: iza@iza.org

\begin{abstract}
Any opinions expressed here are those of the author(s) and not those of IZA. Research published in this series may include views on policy, but the institute itself takes no institutional policy positions. The IZA research network is committed to the IZA Guiding Principles of Research Integrity.

The Institute for the Study of Labor (IZA) in Bonn is a local and virtual international research center and a place of communication between science, politics and business. IZA is an independent nonprofit organization supported by Deutsche Post Foundation. The center is associated with the University of Bonn and offers a stimulating research environment through its international network, workshops and conferences, data service, project support, research visits and doctoral program. IZA engages in (i) original and internationally competitive research in all fields of labor economics, (ii) development of policy concepts, and (iii) dissemination of research results and concepts to the interested public.
\end{abstract}

IZA Discussion Papers often represent preliminary work and are circulated to encourage discussion. Citation of such a paper should account for its provisional character. A revised version may be available directly from the author. 


\section{ABSTRACT}

\section{The Impacts of Vocational Rehabilitation}

Based on local variations in vocational rehabilitation (VR) priorities, we examine the impacts of alternative VR programs on short- and long-term labor market outcomes for temporary disability insurance (TDI) claimants in Norway. The analysis builds on rich and detailed administrative registers covering 345,000 claimants. We find that a strategy focusing on rapid placement in the regular labor market is superior to alternative strategies giving higher priority to vocational training or sheltered employment. Strategies prioritizing subsidized regular education also tend to be relatively successful in terms of final outcomes, but at the cost of protracted periods of benefit dependency first.

JEL Classification: C21, C26, H55, I38, J24

Keywords: vocational rehabilitation, social insurance, treatment effects, program evaluation

Corresponding author:

Knut Røed

The Ragnar Frisch Centre for Economic Research

Gaustadalléen 21

0349 Oslo

Norway

E-mail: knut.roed@frisch.uio.no

\footnotetext{
This paper is part of the project "Effects of vocational rehabilitation programs", financed by the Norwegian ministry of labor. Data made available by Statistics Norway have been essential for the research project.
} 


\section{Introduction}

In all OECD countries, individuals with disabilities have much lower employment rates than the population at large; see, e.g., OECD (2010, p. 51). The evidence is mounting, however, that this state of affairs is not a necessity. Newer research - within economics, epidemiology, and medicine - indicates that disabilities are generally far from incompatible with employment; to the contrary, work can in many cases prevent the onset of disabilities as well as help cure them; see, e.g., Waddell (2004), Waddell and Burton (2006), OECD (2008), and Markussen et al. (2012). Many countries also devote significant resources to various rehabilitation programs aimed at securing employment for the disabled; yet so far with limited success. Rising disability insurance rolls have instead become a major concern in many industrialized countries; see Duggan and Imberman (2006), Burkhauser and Daly (2011), and Bratsberg et al. (2013).

While there already exists a large empirical literature on the impacts of labor market programs targeted at ordinary job seekers (see Kluve et al. (2007) and Card et al. (2010) for recent reviews), there is less evidence on the treatment effects of vocational rehabilitation (VR). Moreover, the existing literature is to a large extent confined to small groups and specific institutional settings, implying low external validity. Scientific evaluations of vocational rehabilitation obviously face huge selection problems, since VR programs are typically only offered to persons deemed by a caseworker both to be in need of a program (due to serious health problems) and to be able to benefit from it. In contrast to what is often assumed for participants in regular labor market programs, the most relevant alternative to a particular vocational rehabilitation program is not necessarily to be untreated, but rather to receive another type of treatment or to receive treatment at another point in time. Many disabled also participate in more than 
one treatment. The distributions of treatment alternatives are likely to vary across different institutional environments, making it difficult to compare studies from different countries. We thus believe that scientific progress in this area - particularly in terms of providing the kind of knowledge that policy-makers demand - requires a clear setting of realistically competing treatment strategies, characterized by well-defined policy parameters.

Our paper relates closely to two existing studies. The first is Frölich et al. (2004), which examines the impacts of vocational rehabilitation programs in Sweden on the basis of nonparametric matching estimators. This study relies on the assumption that all variables that simultaneously affect the VR participation decision and subsequent labor market outcomes are observed. The main conclusions are that there are no favorable effects of VR programs at all, but that workplace rehabilitation is better (less bad) than the alternative strategies of, e.g., "social” rehabilitation or education. The second study is Aakvik, et al. (2005), which examines the impacts of vocational rehabilitation in Norway (for females only) on the basis of a latent variable model motivated by economic theory. This study exploits local variations in the "degree of rationing" to identify the distribution of treatment effects within the framework of a three-equation (one for the treatment decision, one for the outcome if treated, and one for the outcome if nontreated) single-factor model with normally distributed error terms. ${ }^{1}$ The resultant empirical estimates suggest that VR participation has little or no effect on subsequent employment propensities, and that the effects even tend to be negative for actual participants. The estimates are very imprecise, however, and the authors emphasize that they are at best suggestive.

\footnotetext{
${ }^{1}$ The degree of rationing is calculated as the percentage of applicants in local districts who do not participate in the program.
} 
The purpose of the present paper is to provide new and comprehensive empirical evidence on the effectiveness of alternative rehabilitation strategies, based on an empirical approach that exploits (idiosyncratic) local variations in rehabilitation policies as the source of exogenous variation in treatment exposure. This approach relies on the idea that, viewed from the population of disabled individuals, there is an element of randomassignment-like variation in local authorities' treatment priorities. In practice, these local variations are identified by the distribution of observed treatments among other claimants registering in the same treatment environment at approximately the same time (controlled for individual and environmental characteristics and local labor market conditions). Our empirical basis is administrative register data from Norway encompassing the complete population of individuals that entered the temporary disability (TDI) program - and, hence, came under the risk of being referred to vocational rehabilitation from 1996 through 2005. We examine the impacts of vocational rehabilitation strategies on labor market outcomes for a period of up to seven years after entry into TDI, with particular emphasis on subsequent employment, earnings, and social insurance dependency.

While the idea of exploiting local variation in treatment strategies originated from the emergence of qualitative empirical evidence indicating that rehabilitation policies do vary a lot across different social insurance districts in Norway, we will confirm its validity through a rigorous quantitative analysis in this paper. It is notable, however, that the qualitative evidence to a large extent attributes the variation to differences in local "treatment cultures", as well as to inherited practices and program suppliers (Proba, 2012). The resultant differences in treatment practices have been allowed to thrive and persist precisely because "hard" evidence regarding the treatment effects of 
various programs is almost non-existent, leaving plenty of room for local administrators to base their policy choices on a combination of individual judgment, guesswork, personal experience, and convenience.

Our empirical analysis consists of two parts; a "reduced form" analysis, where we examine the impacts of the local treatment environment on subsequent outcomes for all potential participants, and an "instrumental variables" (IV) analysis, where we examine the impacts of actual participation in distinct treatment types, using characteristics of the local treatment environment as instruments. The reduced form analysis identifies the average intention-to-treat-effects of marginal changes in the local "treatment portfolio". A main advantage of this approach is that it is valid even if the treatment environment affects potential participants beyond the impacts associated with actual participation in a particular activity; e.g. by modifying incentives to accept (and search for) jobs or to leave the program for other reasons. It also scores high on the criterion of policyrelevance, since it is the design of rehabilitation institutions and strategies that corresponds most closely to the policy makers' choice variables. A major drawback, however, is that "local treatment strategies" are intrinsically unobserved, and hence bound to be measured with significant error. This biases the estimated reduced form coefficients toward zero. The instrumental variables strategy solves the measurement error problem, and also provides coefficient estimates that are more interpretable than the reduced form coefficients. It identifies the average effects of participating in particular program activities for the sub-population of TDI claimants whose treatment choices are affected by the design of the local treatment environment (the “compliers”). However, the validity of this interpretation requires that the treatment environments affect post-TDI outcomes only through their impacts on actual program participation. Moreover, while we can use 
all TDI spells in the reduced form analysis, we can only use completed spells (for which the realized treatment has been revealed) in the instrumental variables analysis.

An important aim of our analysis is to compare the effectiveness of alternative VR designs, distinguished by their emphasis on employment versus education, by their use of sheltered versus non-sheltered treatment environments, and by their strictness with respect to requiring that vocational rehabilitation has really been tried before a permanent disability insurance (PDI) can be granted. Hence, it is closely related to an ongoing debate in the literature about the respective achievements of the so-called place-and-train and train-and-place rehabilitation strategies, distinguished by their view on whether required skills-upgrading should take place before a placement in the labor market is attempted or vice versa. While empirical research from the U.S. generally finds that a place-and-train strategy is superior to train-and-place (Skinner et al., 2009; Campbell et al., 2011), European evidence is more mixed (Burns et al, 2007; Catty et al., 2008; Howard et al. 2010). Our analysis is also related to a recent U.S. literature, examining labor supply behavior among rejected disability insurance applicants. This literature essentially shows that disability insurance applicants whose claims were rejected due to the assignment of a "strict" judge, do tend to return to the labor market, although with significantly lower earnings than before; see Bound (1989), French and Song (2009), Maestas et al. (2011), and Von Wachter et al. (2011).

Our main finding is that vocational rehabilitation strategies giving high priority to early placement in the regular labor market are the more successful in terms of raising subsequent (non-subsidized) employment and earnings. Strategies emphasizing support for regular education also exhibit favorable post-TDI results, but at the cost of significantly postponing the return to regular employment and self-sufficiency. The alter- 
native strategies - particularly those focusing strongly on sheltered employment and targeted training courses - may in some cases be directly counterproductive. We also find that a stricter admittance practice to permanent disability insurance, conditional on other aspects of the local treatment strategies, strongly reduces the flow into PDI, but has only a small favorable impact on the return-to-work probability, and therefore also only a moderate effect on the overall level of social insurance transfers. The main policy recommendation coming out of our analysis is to focus the vocational rehabilitation strategies more strongly on offering (subsidized) employment in the regular labor market, and to limit the use of training courses and referrals to sheltered firms.

\section{Data and institutional setting}

Vocational rehabilitation in Norway is primarily targeted at persons who have entered the temporary disability insurance (TDI) program. Eligibility to this program requires that at least $50 \%$ of a person's work capacity has been lost due to health problems, and this loss must have been certified by an authorized physician (typically the family doctor). In 2013, there are around 166,000 persons in the TDI program, out of which 60,000 concurrently participate in vocational rehabilitation; see Fevang et al. (2013) for a more thorough description. By comparison, there are around 72,000 unemployed persons in Norway. TDI claimants normally receive a benefit amounting to approximately $66 \%$ of their past earnings (with a floor as well as a ceiling) both when they participate and when they do not participate in a vocational rehabilitation program. The typical entryway to TDI for (former) employees goes through a period of sick pay, which is much more generous (100 \% replacement ratio) than TDI, but can be maintained for only one year. After one year of sick-leave, workers who are unable to take up their regular duties also lose their employment protection, implying that most of them have to find 
something else to do. It is also possible to enter the TDI program without having been employed first, in which case the benefit level is set to the minimum amount (currently around 160,000 NOK (27,000 \$) per year).

The primary purpose of vocational rehabilitation is of course to help people into (or back to) employment, if needed in a new occupation. But it is also used as a sort of screening device for entry into the permanent disability insurance (PDI) program. The Norwegian PDI program has a caseload of 308,000 persons (2013), corresponding to more than $10 \%$ of the working age population, and it has become a major policy priority to curb the inflow. The legislation requires that vocational rehabilitation has been tried before a permanent disability pension can be granted, unless it is deemed by the social insurance administration to be obviously futile. At this point, there is a considerable scope for caseworker judgment, however, and the majority of PDI entrants have never participated in vocational rehabilitation. ${ }^{2}$ Critics nevertheless argue that the requirement leads to a number of half-hearted VR attempts - implemented just for the record. The replacement rate in the PDI program is similar to that in the TDI program, but as indicated by our label, a PDI lasts until it is replaced by an old age pension at the age of 67 , and the claimants are in practice no longer expected to try to return to the labor market.

The starting point for the empirical analysis in this paper is the population of entrants into the temporary disability insurance (TDI) program in Norway, who were between 18 and 57 years at the time of entry. In the period covered by our analysis, the TDI program was administered by the local social insurance administrations (with at least one office in each municipality), whereas the vocational rehabilitation program

\footnotetext{
${ }^{2}$ In our data, as much as $57 \%$ of the recorded transitions to permanent disability occur without vocational rehabilitation having been tried first.
} 
was administered by the employment offices (with one office on average serving around three municipalities). ${ }^{3}$ It was up to the social insurance administration to determine the threshold for admittance into PDI without demanding that vocational rehabilitation had been tried first. If the requirements for PDI were not considered to be met, clients could either be referred to vocational rehabilitation, or they could be given more time to recover through rest or medical treatment and to sort things out on their own. The latter “wait-and-see”-strategy may have the advantage that costly rehabilitation programs are not (superfluously) offered to persons who just need more time to recover. On the other hand, given that vocational rehabilitation is to be implemented anyway, it is costly to postpone it, and one could also worry that long periods of "passive" benefit receipt undermine the work morale and thus reduce the prospects for a successful return to the labor market.

Upon referral to vocational rehabilitation, it was up to the employment office to decide on the timing and contents of the treatment. This decision was typically made on the basis of a combination of the employment office's priorities, the prevailing local capacity constraints, and the claimants own preferences. Somewhat simplified, vocational rehabilitation programs come in four different forms, denoted VR1-VR4; i.e.,

VR1: subsidized employment in regular firms, with or without individual support,

VR2: subsidized employment in sheltered firms,

VR3: regular education in schools/colleges/universities, and

VR4: targeted vocational training courses provided by the employment office.

\footnotetext{
${ }^{3}$ In our data, there are 152 different employment offices and 430 different local social insurance administrations. Starting in 2007, employment offices were merged into the local social insurance offices under a joint labor- and welfare administration.
} 
According to recent cost evaluations (NOU, 2012, p. 85), sheltered employment and regular education are significantly more expensive than the other two alternatives, but there are also considerable cost variations within each of the program categories. In practice, many vocational rehabilitation spells involve participation in more than one category. In order to identify the employment offices' rehabilitation strategy, we will focus exclusively on which of the program categories they tend to choose as the first option for their clients. The implicit assumption is that it is the choice of the first treatment that most clearly reveals an employment office’s priorities.

The data we use in the present paper cover the complete population of entrants into the TDI program from 1996 through 2005. These spells and their outcomes are then tracked until the end of 2010. Table 1 shows some key descriptive statistics. In total, we have around 345,000 TDI spells included in our analysis, and $49 \%$ involved participation in a vocational rehabilitation program. Around half of the vocational programs start out with supported education in regular schools (VR3), a bit less than a quarter start out with a placement in a regular firm (VR1), whereas the remaining treatments are evenly distributed between sheltered employment (VR2) and targeted training courses (VR4). The treated TDI claimants tend to be younger than the non-treated, and also to have had significantly lower previous labor earnings. It is also evident that there are large differences in outcomes between the treated and the non-treated, and also between the four treatment groups; see the lower part of Table 1. In particular, participants in regular education (VR3) appear to have the most successful outcomes, whereas participants in sheltered employment (VR2) have the least successful outcomes. These differences can of course not be given a causal interpretation. 
Table 1. TDI entrants 1996-2005. Descriptive statistics. By first vocational rehabilitation treatment.

Number of entrants

(\% of all entrants in parentheses)

Fraction with previous employment and exhausted sick pay (\%)

Fraction females (\%)

Age at entry

Years of schooling

Immigrant background (\%)

Total earnings, year prior to entry (NOK, 2013 prices)

...of which are labor earnings

...of which are social insurance transfers

Average duration of TDI spells with observed end-date (months)

(\% of spells with observed end-date)

Spells involving more than one VR category (\%)

Selected outcomes

...Average annual labor earnings next five years (NOK, 2013 prices)

...Average annual transf. income next five years (NOK, 2013 prices)

...Employment first year after the end of the TDI spell (\%)

...Permanent disability first year after the end of the TDI spell (\%)

\begin{tabular}{ccccc}
$\begin{array}{c}\text { Non- } \\
\text { Treated }\end{array}$ & VR1 & VR2 & VR3 & VR4 \\
\hline 176,340 & 38,842 & 19,393 & 92,476 & 18,056 \\
$(51.1)$ & $(11.3)$ & $(5.6)$ & $(26.8)$ & $(5.2)$ \\
82.2 & 69.3 & 58.7 & 70.1 & 72.1
\end{tabular}

$\begin{array}{lllll}57.2 & 52.6 & 48.5 & 52.1 & 51.6\end{array}$

$\begin{array}{lllll}42.5 & 37.1 & 38.4 & 35.0 & 37.3\end{array}$

$\begin{array}{lllll}10.6 & 10.5 & 10.1 & 10.6 & 10.4\end{array}$

$\begin{array}{lllll}13.0 & 10.6 & 18.1 & 13.8 & 16.7\end{array}$

$373,901 \quad 312,715 \quad 271,581 \quad 339,088 \quad 331,307$

$337,368 \quad 262,800 \quad 209,762 \quad 287,141 \quad 277,410$

$36,532 \quad 49,916 \quad 61,819 \quad 51,946 \quad 53,896$

$\begin{array}{ccccc}16.3 & 32.9 & 35.0 & 38.1 & 35.3 \\ (97.3) & (65.8) & (62.9) & (59.9) & (59.9) \\ - & 45.0 & 47.2 & 42.1 & 76.6\end{array}$

$\begin{array}{ccccc}163,146 & 123,840 & 67,990 & 130,694 & 115,189 \\ 143,873 & 158,811 & 177,030 & 165,574 & 171,175 \\ 46.2 & 47.6 & 20.4 & 59.8 & 50.4 \\ 40.2 & 35.9 & 47.7 & 20.4 & 27.1\end{array}$

The way we have designed the dataset ensures that all TDI spells are followed in the data for at least five years. Despite that, as much as $20 \%$ of the spells are not completed within our observation period. It follows that there are many very long spells in these data, particularly among claimants who participate in vocational rehabilitation. It is also notable that among the VR-participants, $47 \%$ participate in more than one of the four VR categories during the course of the spell.

\section{Empirical strategy}

The aim of our empirical analysis is to evaluate how local choices of rehabilitation strategies affect the labor market outcomes for those who enter the TDI program. For each client $i$, we define a set of outcome variables $y_{k}$, where the $k$ subscripts refer to the type of outcome (e.g., employment, earnings, social insurance dependency). We are going to estimate a number of linear regression equations where we use these outcomes as 
dependent variables, and variables representing the employment offices' treatment strategies as independent variables together with a large number of controls. Since local treatment strategies are unobserved, we are going to estimate them as well. We do this separately for each claimant, based on the observed choices of treatment for all other claimants registering in the same local treatment environment. Let $\boldsymbol{\varphi}_{\mathrm{i}}$ be the vector of local treatment strategy characteristics relevant for person $i$ (we return the identification and estimation of this vector below). We then specify the reduced form outcome equations as

$$
y_{k i}=\mathbf{x}_{\mathrm{i}}^{\prime} \beta_{k}+\varphi_{\mathrm{i}}^{\prime} \alpha_{k}+\varepsilon_{k i}
$$

where $\mathbf{x}_{\mathbf{i}}$ is a vector of control variables including everything we can think of that might affect individual $i$ 's outcomes apart from the local treatment strategies. This includes individual characteristics (age, gender, education, nationality, past earnings, and past social insurance claims), local area socioeconomic characteristics (average education, average earnings, average mortality, and average disability rate, in all cases adjusted for sex and age and computed for both the municipality and for the employment office areas), local business cycle conditions (unemployment rate, job finding rate for unemployed, job destruction rate for employees, computed for the relevant travel-to-work area for the period from 6 months before to 18 months after entry to TDI), and also entry month indicator variables (to pick up national trends/fluctuations). To avoid unjustified functional form restriction, most of these variables are entered in a non-parametric fashion, implying that we use a large number of dummy variables. Details are provided in the Appendix.

Note that in Equation (1) it is the local treatment strategy that affects person $i$ and not the actual choice of treatment for that person. This reduced form approach iden- 
tifies the average program effects for all TDI-clients, and can be motivated by the idea that local treatment strategies potentially affect outcomes not only through their impacts on actually realized treatments, but also through behavioral responses towards the prospects of being offered - or pushed into - these treatments. If we are willing to assume that such indirect effects are not empirically relevant, it is also possible to estimate the effects of actual participation in the four types of vocational rehabilitation programs by means of an instrumental variables (IV) approach, a point to which we return below. This approach then provides the local average treatment effects (LATE) for the "compliers"; i.e., for the set of TDI clients whose actual treatment outcomes are manipulated by the local treatment strategies.

We now explain how we identify and estimate the local treatment strategyvector $\varphi_{\mathbf{i}}$. It is designed to proxy the characteristics of the treatment environment that person $i$ is exposed to upon entry into the temporary disability insurance program. It consists of five elements, one describing the local social insurance administration's readiness to grant PDI without trying out vocational rehabilitation first, and four elements describing the speed by which still-untreated clients are enrolled into vocational rehabilitation programs of types VR1-VR4, respectively. A treatment environment corresponds to a particular local administrative entity (social insurance office or employment office) and a particular year of entry. This implies that we exploit both the crosssectional variation across different administrative entities and the idiosyncratic variations over time within these entities (national fluctuations are absorbed by the time dummy variables). In a robustness exercise below, we exploit the persistent crosssectional variation only. 
Since the treatment strategy indicators are intended to represent both the choice of (first) treatment, and the speed by which it is implemented, we compute the indicators within the framework of linear discrete transition rate models, where we condition on the same client characteristics $\left(x_{i}\right)$ as those entering the outcome equations. The somewhat unusual choice of linearity in this context is made in order to make it computationally feasible to “remove” each person's influence over the treatment strategy parameters used to explain his/her own outcomes; see below. An important advantage of linearity in this context is also that it effectively prevents differences in functional form assumptions to drive our results. ${ }^{4}$

To illustrate our approach, let $P_{\text {Sijd }}$ be the event of being referred to state $S$, $S=P D I, V R 1, V R 2, V R 3, V R 4$, for claimant $i$ registering in the local treatment environment $j$, and who has been at risk for the event in question in $d$ months ( $P_{S i j d}=1$ if transition $S$ occurs in that month, 0 otherwise). For each entrant to TDI, we include one observation for each month at risk of making a transition to state $S$, starting with the first month after entry. If no event occurs in this month, we add a second month for this entrant, and so forth, until either one of the events in question has occurred or until the TDI spell ends (e.g., because the claimant has found a job). If nothing has happened within a period of 24 months, the spells are right-censored. For each of the five treatment events, we specify a linear probability model as

$$
P_{S i j d}=\mathbf{d}^{\prime} \boldsymbol{\lambda}_{S}+\mathbf{x}_{\mathbf{i}}^{\prime} \boldsymbol{\theta}_{S}+u_{S i j d}
$$

\footnotetext{
${ }^{4}$ Had we estimated local treatment parameters $\varphi_{i}$ with a non-linear model (in the control variables $x_{i}$ ), non-linear direct influences of $x_{i}$ on the various outcomes in Equation (1) could erroneously be captured by the estimated treatment parameters, and thus bias the effects of interest.
} 
where $\mathbf{d}$ is a vector of duration dummy variables $(1,2, \ldots, 24)$ and $\mathbf{x}_{i}$ is the same vector of controls as we use in Equation (1). Now, let $\hat{p}_{s i j d}$ be the predictions from OLS estimation of (2) and let $\hat{u}_{S i j d}$ be the corresponding residuals. Furthermore, let $D_{S i}$ be the realized duration at which individual $i$ was under risk of the event in question. We then have that the sum of individual $i$ 's residuals can be written

$$
\hat{u}_{S i j}=\sum_{d=1}^{D_{S i j}} \hat{u}_{S i j d}=P_{S i D_{i}}-\sum_{d=1}^{D_{S i}} \hat{p}_{S i j d}
$$

On average, the sums of individual residuals are by construction equal to zero. To illustrate their interpretation, we abstract for a moment from right-censoring and duration dependence, and denote the (then) constant event probability $\hat{p}_{S i j}$. The right-hand side of (3) then simplifies to $1-D_{s i} \hat{p}_{s i j}$. Since expected duration until an event for person $i$ is the inverse of the event probability $\left(E\left(D_{s i}\right)=1 / \hat{p}_{s i j}\right)$, we also have that $\hat{u}_{S i j}=-\left(D_{S i}-E\left[D_{S i}\right]\right) \hat{p}_{S i j}$, i.e., $\hat{u}_{S i j}$ is equal to minus the number of "excess" waiting months (compared to what we would expect on the basis of $\mathbf{x}_{\mathbf{i}}$ ), weighted by the transition probabilities. If the sum of individual residuals is positive (negative), the claimant has made the transition in question more quickly (slowly) than what would be predicted on the basis of observed characteristics, and the weight attributed to a given deviation is larger the less likely it is to occur. The sum $\hat{u}_{s i j}$ can thus be interpreted as the estimated covariate-adjusted transition propensity at the claimant level. A natural indicator for the local treatment environment's contribution to this propensity is therefore the average sum of residuals among its clients; i.e.

$$
\varphi_{S j}=\left(N_{j}\right)^{-1} \sum_{i \in N_{j}} \hat{u}_{S i j},
$$


where $N_{j}$ is the number of clients subject to treatment environment $j$ (defined by administrative entity and year of entry).

A potential problem with using $\varphi_{S j}$ directly as a covariate in relation to person i's outcomes in Equation (1) is that we have used the treatment outcome for that very same person to estimate it. Hence, if there is a correlation between the residuals in Equations (1) and (2) - which seems plausible - our estimates of causal effects will be biased. We deal with this problem by removing client $i$ from the computation of his/her own local rehabilitation strategy indicators. We then compute the local treatment strategy parameters relevant for person $i$ as

$$
\varphi_{S j,-i}=\frac{N_{j} \varphi_{S j}-\hat{u}_{S i j}}{N_{j}-1} .
$$

which is then exogenous to individual $i$, provided that the distribution of clients to treatment environments can be considered as good as randomly assigned, conditional on $\mathbf{x}_{\mathbf{i}}$. Hence, it is important that $\mathbf{x}_{\mathbf{i}}$ is sufficiently rich and flexible to account for the residential sorting into the different social insurance districts. If treatment environments with, say, particularly high measured PDI propensities also systematically tend to have clients with particularly poor employment prospects after $\mathbf{x}_{\mathbf{i}}$ is controlled for, this condition is violated. We return to this issue below in a series of robustness and placebo analyses. It is also clear that our treatment strategy indicators are at best proxies for some unobserved true local treatment strategies; i.e., they are measured with error. This implies that the estimated impacts of the treatment strategies will be biased toward zero. Hence, in this sense, our estimates may be viewed as lower bounds on the true effects.

For post-TDI outcomes, we also estimate an instrumental variables model where we use observed program participation directly as explanatory variables, and instrument 
them with the vector of local program intensity indicators in $\boldsymbol{\varphi}_{\mathbf{i}}$. Let $\mathbf{P}_{i}=\left\{P_{1 i}, P_{2 i}, P_{3 i}, P_{4 i}\right\}$ be a vector of variables indicating that a treatment starting with the corresponding type of VR program was initiated at some time during a TDI spell. We then write the outcome equations as

$$
y_{k i}=\mathbf{x}_{\mathbf{i}} \gamma_{k}+\mathbf{P}_{\mathbf{i}} \mu_{k}+\tau \varphi_{P D I j,-i} \eta_{k i}
$$

Here, $\mu_{k}$ can be interpreted as the effects of actually participating in the different programs compared to being non-treated, regardless of when the first transition to treatment occurred. Since the elements in $\mathbf{P}_{\mathbf{i}}$ are likely to be highly correlated with the residuals $\eta_{k i}$, we instrument them by the corresponding indicators computed in Equation (5), i.e., $\left\{\varphi_{V R 1 j,-i}, \varphi_{V R 2 j,-i}, \varphi_{V R 3 j,-i}, \varphi_{V R 4 j,-i}\right\}$. This implies that if the true effects of program participation are heterogeneous - which seems plausible - our estimates will have a local average treatment effect (LATE) interpretation; i.e., for each program, the estimated effect is representative for the sub-population whose participation in that particular program is manipulated by the local treatment strategy parameters. ${ }^{5}$ Since these parameters also can be interpreted directly as the labor market authorities' decision variables, the IV-strategy yields treatment effect estimates of high policy relevance. It also solves the errors-in-variables problem referred to above, since the measurement error is corrected for through the first step estimation where individual treatment outcomes are regressed on the treatment strategy proxies. Validity of IV model requires, however, that the local

\footnotetext{
${ }^{5}$ Given that we have all four endogenous and mutually exclusive treatment outcomes simultaneously as right-hand-side variables in Equation (6), it is perhaps not obvious that the IV (two-step least squares) coefficients are consistent estimators for the true treatment effects relative to non-treatment for the respective complier groups. We have therefore verified this interpretation by means of a Monte Carlo (MC) experiment where we generated multiple treatments with a data-generating process similar to the one used here. A brief description of the MC experiment and its results are available here: http://www.frisch.uio.no/docs/MC_multi_treatment.html
} 
treatment strategies affect the TDI claimants through the probabilities of actual participation only.

Our methodological approach is similar in spirit to the one used by Duggan (2005) to characterize psychiatrists’ propensities to prescribe particular drugs, by Doyle (2008) to characterize child protection investigators' propensities to place children in foster care, and by Markussen et al. (2012) to characterize physicians’ propensities to impose activity requirements on sick-listed workers.

\section{The local treatment strategies}

How important are the local treatment strategies for actual treatment events? To answer this question we add the strategy indicators $\left(\varphi_{i}\right)$ into the duration models in Equation (2), and examine their predictive power for actual choices of treatment strategies. Some results are given in Table 2 . To facilitate interpretation, we have scaled the treatment policy indicators such that a unit difference corresponds to the average difference (taken over all 10 years) between the local administrations using the respective strategies least and most; hence the reported parameters can be interpreted as the expected percentage point change in monthly entry probabilities resulting from a movement from the treatment environment giving lowest priority to the strategy under consideration to the one giving it highest priority. Recall, however, that measurement error will tend to bias these coefficients toward zero.

It is evident from Table 2 that the local treatment strategies have significant impacts on the claimants' treatment outcomes. As expected, it is the propensity to use the treatment strategy under consideration that is most important (the diagonal elements in Table 2). In addition, we find that a high local propensity to grant permanent disability 
insurance entails high transition rates to all the vocational rehabilitation programs. Our interpretation of this finding is that social insurance offices with high PDI propensity tend to be offices with low waiting time for caseworker decisions in general, implying that they also tend to refer claimants quickly to the employment offices. ${ }^{6}$ The large and distinct effects that the four VR-intensities have on actual program participation implies that they have a considerable potential in terms of revealing the causal effects of local VR strategies, and that they also constitute powerful instruments in an IV-setting

Table 2. Estimated effects of standardized treatment policy parameters on treatment events (standard errors in parentheses)

\begin{tabular}{|c|c|c|c|c|c|}
\hline & VR1 & VR2 & VR3 & VR4 & PDI \\
\hline VR1-intensity $\left(\varphi_{\mathrm{VR} 1 j,-i}\right)$ & $\begin{array}{c}1.031^{* * *} \\
(0.026)\end{array}$ & $\begin{array}{c}0.019 \\
(0.018)\end{array}$ & $\begin{array}{c}-0.036 \\
(0.041)\end{array}$ & $\begin{array}{c}-0.014 \\
(0.018)\end{array}$ & $\begin{array}{c}0.000 \\
(0.038)\end{array}$ \\
\hline VR2-intensity $\left(\varphi_{V R 2 j,-i}\right)$ & $\begin{array}{c}0.016 \\
(0.021)\end{array}$ & $\begin{array}{c}0.802 * * * \\
(0.014)\end{array}$ & $\begin{array}{c}-0.049 \\
(0.032)\end{array}$ & $\begin{array}{c}-0.020 \\
(0.014)\end{array}$ & $\begin{array}{c}0.020 \\
(0.030)\end{array}$ \\
\hline VR3-intensity $\left(\varphi_{V R 3 j,-i}\right)$ & $\begin{array}{c}-0.025 \\
(0.025)\end{array}$ & $\begin{array}{c}-0.028 * \\
(0.017)\end{array}$ & $\begin{array}{c}1.749 * * * \\
(0.039)\end{array}$ & $\begin{array}{c}-0.019 \\
(0.022)\end{array}$ & $\begin{array}{c}0.016 \\
(0.034)\end{array}$ \\
\hline VR4-intensity $\left(\varphi_{V R 4 j,-i}\right)$ & $\begin{array}{c}-0.031 * * \\
(0.013)\end{array}$ & $\begin{array}{c}-0.017^{*} \\
(0.009)\end{array}$ & $\begin{array}{c}-0.033 \\
(0.021)\end{array}$ & $\begin{array}{c}0.703^{* * *} \\
(0.009)\end{array}$ & $\begin{array}{c}0.060 * * * \\
(0.020)\end{array}$ \\
\hline PDI-intensity $\left(\varphi_{P D I j,-i}\right)$ & $\begin{array}{l}0.034 * \\
(0.020)\end{array}$ & $\begin{array}{c}0.059 * * * \\
(0.013)\end{array}$ & $\begin{array}{c}0.066 * * \\
(0.030)\end{array}$ & $\begin{array}{c}0.047 * * * \\
(0.014)\end{array}$ & $\begin{array}{c}2.000 * * * \\
(0.027)\end{array}$ \\
\hline Average monthly transition probability (\%) & 0.76 & 0.35 & 1.86 & 0.37 & 1.21 \\
\hline $\begin{array}{l}\text { Fraction of variance in predicted transition } \\
\text { rates accounted for by } \varphi_{i}(\%)\end{array}$ & 12.50 & 29.64 & 4.98 & 48.82 & 5,53 \\
\hline $\mathrm{N}$ & 345,118 & 345,118 & 345,118 & 345,118 & 345,118 \\
\hline
\end{tabular}

Additional insights to the role of local treatment strategies may be gained by comparing the isolated predictive power of the strategy indicators $\left(\varphi_{\mathrm{i}}\right)$ with the corresponding power of all explanatory variables taken together $\left(\mathbf{x}_{\mathbf{i}}, \mathbf{d}, \boldsymbol{\varphi}_{\mathbf{i}}\right)$. At the bottom of Table 2, we report the fraction of the variance in predicted monthly transition probabilities that can be accounted for by the local treatment strategy parameters. The numbers

\footnotetext{
${ }^{6}$ Recall that PDI-decisions are taken at a more local level (social insurance offices) than VRdecisions (employment offices). This is the reason why the PDI-intensity can have distinct effects on program entry decisions, even controlled for the VR-intensities.
} 
range from $4.98 \%$ for regular education programs (VR3) to $48.82 \%$ for targeted courses run by the employment office itself (VR4). Thus, for explaining local treatment choices, individual factors and labor market conditions are more important than local treatment strategies, but the latter are far from negligible.

\section{Main results}

In this section, we examine the impacts of the treatment policy parameters on a number of different labor market outcomes, based on alternative versions of Equations (1) and (6). The outcomes are designed to represent measures of labor market performance and social insurance dependency over both short-term and long-term horizons. We distinguish between outcomes that are conditioned on the TDI spell being ended (post-TDI outcomes) and outcomes that are unconditional of this event.

We use four post-TDI outcomes; two dichotomous variables indicating whether the spell was followed by regular employment or by permanent disability (PDI), respectively, and two income measures reporting the labor earnings and social security transfers, respectively, in the first calendar year after completion of the TDI spell. ${ }^{7}$ These measures may indicate the extent to which the treatment environment affected the ultimate outcome of the TDI spell, but are not informative with respect to how long it took to get there. ${ }^{8}$ For the post-program outcomes, we also compute instrumental variables estimates of the effects of actually participating in one of the four VR program strate-

\footnotetext{
${ }^{7}$ Our definition of employment is derived directly from the level of annual earnings; i.e., we assume that a person is employed in a given year if the labor-related earnings in that year exceeded approximately 160,000 NOK (measured in 2013 prices), corresponding to around 27,000 \$.

${ }^{8}$ From the descriptive statistics in Table 1, we recall that while virtually all (97.3\%) non-treated spells ended within our observation window, this was the case for only around $60-65 \%$ of the treated spells. Hence, the dataset that can be used to examine post-TDI outcomes constitute a selected subsample of all spells. This "selection problem" appears to be of minor importance for our results, however. When we drop entrants during the last three entry-years, the estimates do not change to any noticeable extent.
} 
gies. However, as discussed above, the interpretation of these estimates as local average treatment effects of actual participation hinges on the assumptions that the treatment strategies affect outcomes through their impacts on actual participation only and that the effects among those with completed and uncompleted spells in the data are of similar magnitudes. Even though these assumptions are disputable, we believe that the instrumental variables estimates are of value as they offer one - though not the only - reasonable interpretation of the more robust reduced form findings, and thus give us a clearer idea of the magnitudes involved. In particular, if non-participants are also affected by the chosen treatment strategies whereas the sorting problem associated with focusing on completed spells only is ignorable, the IV estimates may be interpreted as lower bounds on the overall effects per unit of treatment, and hence still be highly informative from a policy perspective. The reason why we interpret the estimates as lower bounds in this case it that when the effects are not exclusively derived from actual participation, the IV approach does not fully remove attenuation bias caused by measurement error.

In the reduced form analysis, we also use several outcome indicators that are not conditional on the TDI-spell being ended. In particular, we use two summary measures reporting average annual labor earnings and social security transfers, respectively, over the five year period following just after TDI entry. These outcome measures are available for the full sample of TDI claimants. In addition, we use the same earnings outcomes year by year, from the first year after entry and up to seven years after entry. ${ }^{9}$ One important caveat regarding these earnings measures is that during participation in VR programs, a salary paid out by an employer is classified as labor earnings even if the employer receives a wage subsidy from the social security administration. Hence, as a

\footnotetext{
${ }^{9}$ For outcomes looking beyond the fifth year, the sample is reduced, as entrants in 2004 (2005) can be followed for only 6 (5) years.
} 
“cleaner” measure of labor market success, we also include a dichotomous year-byyear-outcome indicating that that a person has both completed the TDI-spell and become employed (without any form of subsidies).

Table 3 reports the reduced form impacts of the local treatment strategies on the post-program outcomes and on average annual labor and social insurance earnings during the first five years after entry into the program, whereas Figure 1 shows the estimated annual effects year by year. The instrumental variables estimates of the effect of actual VR participation on post-program outcomes are reported in Table 4.

Table 3. Estimated effects of standardized treatment policy parameters on labor market outcomes (standard errors in parentheses)

\begin{tabular}{|c|c|c|c|c|c|c|}
\hline \multirow[b]{3}{*}{$\begin{array}{l}\text { VR1- } \\
\text { intensity }\end{array}$} & \multicolumn{4}{|c|}{ Post TDI outcomes (first year after end of TDI) } & \multicolumn{2}{|c|}{ Av. earnings $1-5$ years after entry } \\
\hline & $\begin{array}{c}\text { I } \\
\text { Employment } \\
\text { (p.p.) }\end{array}$ & $\begin{array}{c}\text { II } \\
\text { Labor earnings } \\
(\mathrm{NOK})\end{array}$ & $\begin{array}{c}\text { III } \\
\text { Permanent } \\
\text { disability (p.p.) }\end{array}$ & $\begin{array}{c}\text { IV } \\
\text { Social insur- } \\
\text { ance transfers } \\
\text { (NOK) }\end{array}$ & $\begin{array}{c}\mathrm{V} \\
\text { Labor earnings } \\
(\mathrm{NOK})\end{array}$ & $\begin{array}{c}\text { VI } \\
\text { Social insur- } \\
\text { ance transfers } \\
\text { (NOK) }\end{array}$ \\
\hline & $\begin{array}{c}1.098^{* *} \\
(0.051)\end{array}$ & $\begin{array}{c}4,982^{* *} \\
(1,955)\end{array}$ & $\begin{array}{c}-1.070^{*} \\
(0.644)\end{array}$ & $\begin{array}{c}-5,488 * * * \\
(1,343)\end{array}$ & $\begin{array}{c}5,723^{* * *} \\
(1,457)\end{array}$ & $\begin{array}{c}-5,780 * * * \\
(1,049)\end{array}$ \\
\hline $\begin{array}{l}\text { VR2- } \\
\text { intensity }\end{array}$ & $\begin{array}{c}-1.679 * * * \\
(0.042)\end{array}$ & $\begin{array}{c}-4,397 * * * \\
(1,597)\end{array}$ & $\begin{array}{c}0.881 \\
(0.592)\end{array}$ & $\begin{array}{c}1,220 \\
(1,205)\end{array}$ & $\begin{array}{l}-1,434 \\
(1,297)\end{array}$ & $\begin{array}{c}-22 \\
(917)\end{array}$ \\
\hline $\begin{array}{l}\text { VR3- } \\
\text { intensity }\end{array}$ & $\begin{array}{c}1.267 * * \\
(0.051)\end{array}$ & $\begin{array}{c}6,881^{* * *} \\
(1,916)\end{array}$ & $\begin{array}{c}-2.727 * * * \\
(0.569)\end{array}$ & $\begin{array}{c}-2,623 * * \\
(1,275)\end{array}$ & $\begin{array}{c}-6,206^{* * *} \\
(1,421)\end{array}$ & $\begin{array}{c}5,510^{* * *} \\
(954)\end{array}$ \\
\hline $\begin{array}{l}\text { VR4- } \\
\text { intensity }\end{array}$ & $\begin{array}{c}-0.749 * * \\
(0.334)\end{array}$ & $\begin{array}{c}-3,199 * * \\
(1,374)\end{array}$ & $\begin{array}{c}0.396 \\
(0.330)\end{array}$ & $\begin{array}{l}1,550 \\
(840)\end{array}$ & $\begin{array}{c}-2,719 * * * \\
(906)\end{array}$ & $\begin{array}{c}1,279 * \\
(577)\end{array}$ \\
\hline $\begin{array}{l}\text { PDI- } \\
\text { intensity }\end{array}$ & $\begin{array}{c}-1.700^{* * *} \\
(0.041)\end{array}$ & $\begin{array}{c}-6,486 * * * \\
(1,589)\end{array}$ & $\begin{array}{c}8.162 * * * \\
(0.494)\end{array}$ & $\begin{array}{c}6,921^{* * *} \\
(1,089)\end{array}$ & $\begin{array}{c}-5,210^{* * *} \\
(1,271)\end{array}$ & $\begin{array}{c}4,625^{* * *} \\
(855)\end{array}$ \\
\hline $\mathrm{N}$ & 274,494 & 274,494 & 275,622 & 274,494 & 345,101 & 345,101 \\
\hline
\end{tabular}

Notes: VR and PDI intensities are normalized such that a unit difference corresponds to the average difference (taken over all 10 years) between the two local administrations using the respective strategies least and most. Coefficients report impacts measured in percentage points (columns I and III) or NOK (measured in 2013 prices). List of additional control variables used in all the regressions is provided in the Appendix. The number of observations $(\mathrm{N})$ used for the post-program outcomes is reduced due the presence of non-completed spells. $\mathrm{N}$ is slightly higher for the PDI outcome for the reason that these outcomes are observed with more accurate timing, and hence do not require a full posttreatment calendar year to be identified. The reported standard errors are robust, clustered on treatment environments (social insurance districts by year).

$*(* *)(* * *)$ Significant at the $10(5)(1) \%$ level. 
Labour earnings
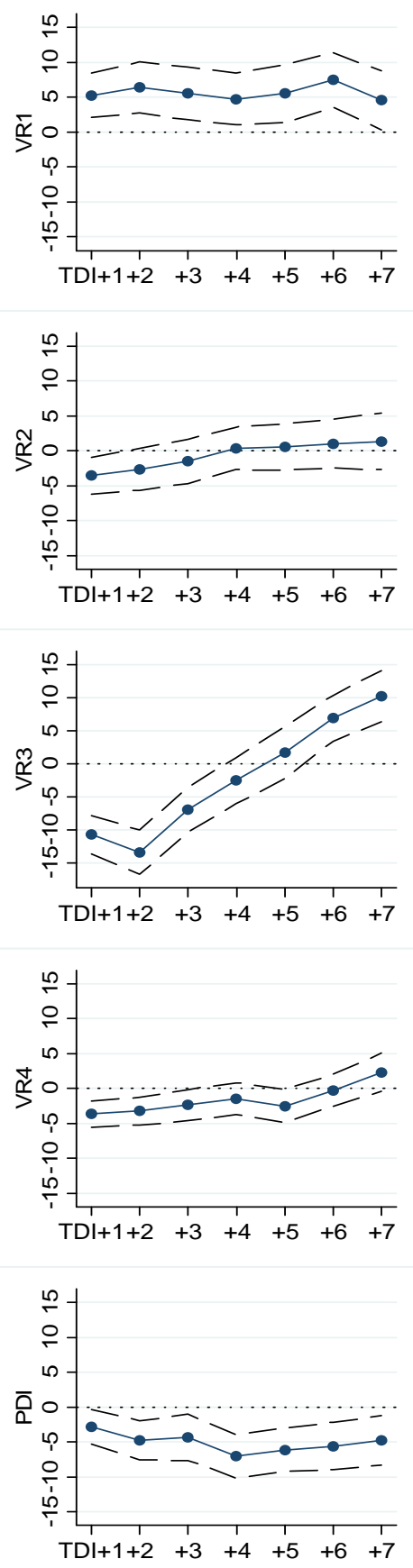

Social security earnings
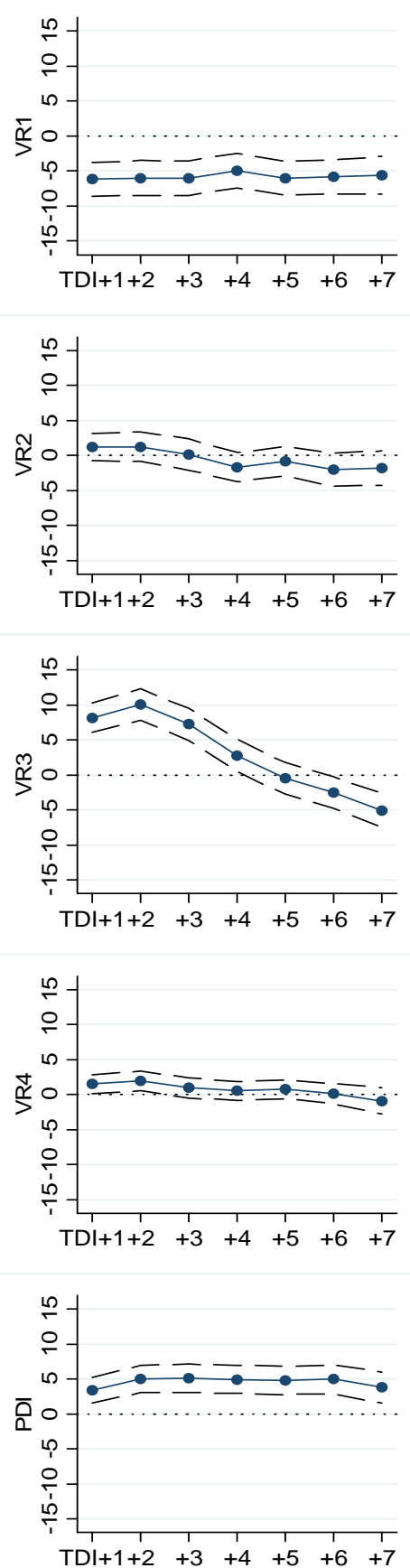

Employment without TDI
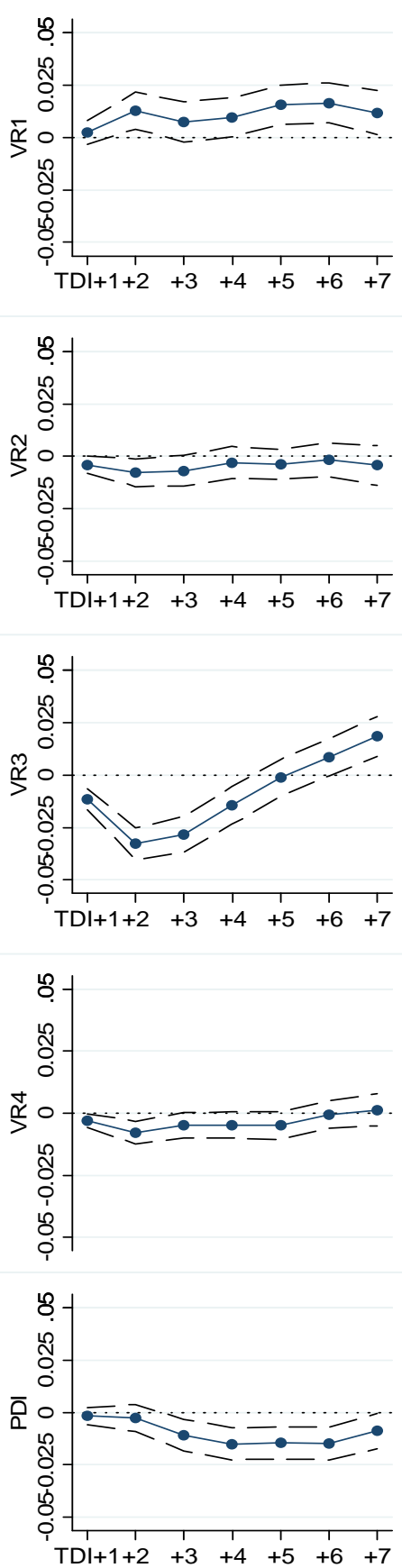

Figure 1. Estimated impacts of local treatment policy parameters (with $95 \%$ confidence intervals).

Notes: The horizontal axes show years after the year of entry into TDI. The vertical axes show 1000 NOK (measured in 2013 value) for the two earnings outcomes and percentage points for the dichotomous employment outcome. See also notes to Table 3. 
Table 4. Instrumental variables estimates of VR-participation on post-TDI outcomes first year after end of TDI (standard errors in parentheses)

\begin{tabular}{|c|c|c|c|c|}
\hline $\begin{array}{l}\text { Actual participation } \\
\text { in: }\end{array}$ & $\begin{array}{l}\text { I } \\
\text { Employment } \\
\text { (p.p.) }\end{array}$ & $\begin{array}{c}\text { II } \\
\text { Labor earnings } \\
\text { (NOK) }\end{array}$ & $\begin{array}{c}\text { III } \\
\text { Permanent disability } \\
\text { (p.p.) }\end{array}$ & $\begin{array}{c}\text { IV } \\
\text { Social insurance } \\
\text { transfers (NOK) }\end{array}$ \\
\hline VR1 & $\begin{array}{c}11.664 * * \\
(5.738)\end{array}$ & $\begin{array}{c}56,731^{* * *} \\
(21,975)\end{array}$ & $\begin{array}{l}-12.935^{*} \\
(7.259)\end{array}$ & $\begin{array}{c}-61,804 * * * \\
(15,299)\end{array}$ \\
\hline VR2 & $\begin{array}{l}-18.950 * * * \\
(5.210)\end{array}$ & $\begin{array}{c}-45,726 * * \\
(19,671)\end{array}$ & $\begin{array}{c}8.254 \\
(7.258)\end{array}$ & $\begin{array}{c}7,555 \\
(14,941)\end{array}$ \\
\hline VR3 & $\begin{array}{c}10.715^{* *} \\
(4.216)\end{array}$ & $\begin{array}{c}59,287 * * * \\
(15,795)\end{array}$ & $\begin{array}{c}-22.699 * * * \\
(4.748)\end{array}$ & $\begin{array}{c}-29,424 * * * \\
(10,717)\end{array}$ \\
\hline VR4 & $\begin{array}{l}-11.844^{* *} \\
(5.996)\end{array}$ & $\begin{array}{l}-47,702 * \\
(24,593)\end{array}$ & $\begin{array}{l}-3.957 \\
(5.990)\end{array}$ & $\begin{array}{c}11,842 \\
(15,282)\end{array}$ \\
\hline $\mathrm{N}$ & 274,494 & 274,494 & 275,622 & 274,494 \\
\hline
\end{tabular}

Notes: Coefficients report impacts measured in percentage points (columns I and III) or NOK (measured in 2013 prices). List of additional control variables used in all the regressions is provided in the Appendix. The number of observations $(\mathrm{N})$ is slightly higher for the PDI outcome (Column III) for the reason that these outcomes are observed with more accurate timing, and hence do not require a full post-treatment calendar year to be identified. The reported standard errors are robust, clustered on treatment environments. $*(* *)(* * *)$ Significant at the 10(5)(1) \% level.

We now briefly discuss the results for each of the treatment strategies in turn. Giving priority to subsidized employment in the regular labor market (VR1) appears to be a successful strategy. It raises the claimants' probability of moving on to nonsubsidized employment and reduces their risk of ending up with permanent disability insurance; see Table 3. It also raises the probability of quitting the TDI spell with a regular job already the first year after entry, with a further increase in the subsequent years; see Figure 1. The estimated impacts of moving from the treatment environment with lowest to the one with the highest VR1-intensity is predicted to raise the post TDI employment propensity by 1.098 percentage points and labor earnings by 4,982 NOK (approximately 835 \$). These numbers should be treated with some care, since measurement errors of unknown magnitude probably have biased them toward zero. Relative impacts are less affected by this problem. Hence, we may safely conclude that, e.g., a VR1-strategy tends to raise employment and earnings with approximately the same numbers as it reduces permanent disability and social insurance transfers. If the higher 
earnings following from a more intensive VR1 strategy are exclusively allocated to the additional employees, we can also compute that the average annual earnings level for each extra employee is around 453,000 NOK (4,982/0.01098) (76,000 \$), which is just slightly below the average earnings level in Norway. ${ }^{10}$

Moving on to the instrumental variables estimates in Table 4, we find that the estimated effects of actually participating in VR1 as opposed to receive no treatment at all are to raise the expected annual labor earnings once the TDI spell is over by 56,731 NOK and to reduce the expected social insurance transfers with a similar amount. The chances of becoming employed rises by $11.67 \%$. Hence, the IV-estimates indicate an earnings gain per additional employee around 486,000 NOK (81,000 \$).

In terms of post-TDI outcomes, prioritizing regular education (VR3) also appears to be a very successful strategy. Its effects on employment and earnings are similar to those estimated for VR1, and in addition it significantly reduces the probability of transition to permanent disability insurance. However, in contrast to VR1, strategies focusing on VR3 also have a significant cost-side, in terms of large lock-in effects during the first years after entry. This can be seen by the significant drop in labor earnings and the corresponding increase in social insurance transfers over the first years after entry; see Figure 1.

Prioritizing placement in a sheltered labor market (VR2) is, according to our estimates, a rather questionable strategy. It actually reduces the chances for ending up with a regular (non-subsidized) job, and also reduces the level of post-TDI labor earnings. Similarly, prioritizing more targeted (and shorter) vocational training courses (VR4) also have negative effects on both employment and labor earnings.

\footnotetext{
${ }^{10}$ In comparison, the average fulltime-equivalent annual salary for all employees in Norway was approximately 495,000 in 2011 (also inflated to 2013-prices).
} 
A more liberal admittance practice to permanent disability (PDI) unsurprisingly raises the probability that TDI spells end with PDI. Moving from the "strictest" to the most "lenient” local PDI environment identified in our data raises the probability that the spell ends with permanent disability by as much as 8.2 percentage points. There are also indications that it reduces the chances that the spell ends with employment, although with the much smaller effect of 1.7 percentage points. Since admittance strictness apparently has a much larger effect on PDI admittance itself than on employment, it follows that the variations in inflows to PDI along this margin primarily substitute for other forms of inactivity or unemployment. This is also consistent with the finding of a relatively moderate effect of PDI leniency on the overall level of social insurance transfers in the year after TDI completion (6,921 NOK; see Table 3). This suggests that the variations in PDI leniency to a large extent are offset by variations in the payments of other transfers (particularly social assistance).

\section{Robustness and reliability}

Can we trust these results? Since we have used non-experimental data to identify causal effects, some doubt inevitably remains. What if local treatment environments with particular emphasis on, say, VR1, also tend have a positively selected group of TDI claimants and/or operate in areas with particularly favorable labor market developments? Our first line of defense against this doubt would of course be that we have controlled for these potential differences in a highly non-restrictive fashion, taking full advantage of extremely rich data sources; see the Appendix. However, there may still exist unobserved differences that drive our results. In this section, we assess the potentiality of selection bias by conducting a robustness check and by running different types of "placebo-regressions”. 
If local treatment strategies respond to local cyclical fluctuations in a way unaccounted for by our business cycle indicators, our estimators could be confounded by reverse causation. To assess this potential problem, we re-estimate all our models on the basis of treatment strategy indicators that are constant over time across local administrations. This implies that we treat each local administrative entity as representing the same treatment environment throughout the data period, and that the corresponding indexes are obtained by summing over all residuals belonging to the entities in question in Equation (4), regardless of year of entry. Hence, in this exercise, we only exploit the persistent cross-sectional variation in treatment strategies.

Table 5. Robustness analysis. Instrumental variables estimates of VR-participation on post-TDI outcomes with constant treatment strategy indicators (no time-variation within administrative units) used as instruments (standard errors in parentheses)

\begin{tabular}{|c|c|c|c|c|}
\hline $\begin{array}{l}\text { Actual participation } \\
\text { in: }\end{array}$ & $\begin{array}{c}\text { I } \\
\text { Employment } \\
\text { (p.p.) }\end{array}$ & $\begin{array}{c}\text { II } \\
\text { Labor earnings } \\
\text { (NOK) }\end{array}$ & $\begin{array}{c}\text { III } \\
\text { Permanent disability } \\
\text { (p.p.) }\end{array}$ & $\begin{array}{c}\text { IV } \\
\text { Social insurance } \\
\text { transfers (NOK) }\end{array}$ \\
\hline VR1 & $\begin{array}{l}23.448 * * * \\
(8.269)\end{array}$ & $\begin{array}{c}89,778 * * * \\
(30,382)\end{array}$ & $\begin{array}{c}-6.399 \\
(13.503)\end{array}$ & $\begin{array}{c}-83,125^{* * *} \\
(20,406)\end{array}$ \\
\hline VR2 & $\begin{array}{c}-24.034^{* *} \\
(9.351)\end{array}$ & $\begin{array}{l}-67,751^{*} \\
(36,170)\end{array}$ & $\begin{array}{c}25.159 \\
(19.220)\end{array}$ & $\begin{array}{c}32,858 \\
(34,645)\end{array}$ \\
\hline VR3 & $\begin{array}{l}10.407 \\
(7.074)\end{array}$ & $\begin{array}{c}63,076^{* *} \\
(24,021)\end{array}$ & $\begin{array}{c}-26.721 * * * \\
(9.336)\end{array}$ & $\begin{array}{l}-29,719 \\
(19,028)\end{array}$ \\
\hline VR4 & $\begin{array}{l}-17.280 \\
(13.510)\end{array}$ & $\begin{array}{l}-52,210 \\
(52,274)\end{array}$ & $\begin{array}{c}-7.531 \\
(21.573)\end{array}$ & $\begin{array}{l}-19,887 \\
(36,864)\end{array}$ \\
\hline $\mathrm{N}$ & 274,500 & 274,500 & 275,628 & 274,500 \\
\hline \multicolumn{5}{|c|}{$\begin{array}{l}\text { Notes: Coefficients report impacts measured in percentage points (columns I and III) or NOK (measured in } 2013 \\
\text { prices). List of additional control variables used in all the regressions is provided in the Appendix. The number o } \\
\text { observations }(\mathrm{N}) \text { is slightly higher for the PDI outcome (Column III) for the reason that these outcomes are observec } \\
\text { with more accurate timing, and hence do not require a full post-treatment calendar year to be identified. The reportec } \\
\left.\text { standard errors are robust, clustered on administrative units. }{ }^{* * *}\right)(* * *) \text { Significant at the } 10(5)(1) \% \text { level. }\end{array}$} \\
\hline
\end{tabular}

For ease of comparison, we focus on the instrumental variables estimates in this robustness exercise. ${ }^{11}$ What happens when we use treatment strategy indicators that are constant within each administrative unit is that virtually all the estimated impacts be-

\footnotetext{
${ }^{11}$ It is more difficult to compare the reduced form estimates, since the variation in the estimated treatment strategy indexes are much larger when they vary by both district and year than when they vary by district only. All the qualitative conclusions are the same, however.
} 
come a bit larger; see Table 5. At the same time, the sizes of the standard errors rise considerably, reflecting the significant loss of variation in the instruments. All the major conclusions remain unchanged, however.

As a further check for remaining bias, we also run "placebo"-regressions, using past earnings as the outcome measure instead of future earnings. For this purpose, we use the same sample of TDI-spells and the exact same statistical reduced form model as we use in our main analysis. Since we have conditioned on earnings 1-3 year before entry, our "placebo" outcomes are in this case average earnings 4 and 5 years before entry to TDI, respectively. If there is a systematic correlation between the choice of local treatment strategies and the resources of the claimant population, it is probable that this show up in "effects" on past earnings as well as on future earnings. As is clear from the results in Table 6, there is no indication of bias in this sense.

Table 6. Results from placebo regressions (standard errors in parenthesis)

\begin{tabular}{lcc}
\hline & $\begin{array}{c}\text { Average earnings } 4 \text { years before } \\
\text { (NOK) }\end{array}$ & $\begin{array}{c}\text { Average earnings } 5 \text { years before } \\
\text { (NOK) }\end{array}$ \\
\cline { 2 - 3 } VR1-intensity & -975 & $-2,579$ \\
& $(1,329)$ & $(1,693)$ \\
VR2-intensity & $-1,273$ & -271 \\
& $(1,017)$ & $(1,233)$ \\
VR3-intensity & 1,616 & 463 \\
& $(1,145)$ & $(1,345)$ \\
VR4-intensity & 451 & 530 \\
& $(650)$ & $(793)$ \\
PDI-intensity & -366 & 221 \\
N & $(1,108)$ & $(1,316)$ \\
\hline
\end{tabular}

Notes: VR and PDI intensities are normalized such that a unit difference corresponds to the average difference (taken over all 10 years) between the two local administrations using the respective strategies least and most. All outcomes are measured in NOK and inflated to the 2013 price level. Reduced sample sizes for the TDI claimants reflect missing information on past earnings. List of additional control variables used in all the regressions is provided in the Appendix. The reported standard errors are robust, clustered on social insurance districts. ${ }^{*}(* *)(* * *)$ Significant at the 10(5)(1) \% level.

As a final test for confounders related to local cyclical fluctuations, we investigate whether our treatment strategy indicators are correlated with outcomes for locals who did not participate in TDI. In this exercise we use the exact same statistical reduced 
form model as in the main analysis, and also the same future 5-year earnings outcome. We look at two different populations. The first is a set of matched groups of locals with no relationship to the social insurance and employment offices at the time of matching to a TDI entrant. This is done in the following way: For each TDI claimant, we find a non-client who lives in the same neighborhood, who has the same sex, is of approximately the same age (+/- 2 years), and has the same level and type of education (35 different categories). ${ }^{12}$ If treatment strategies are correlated to uncontrolled for local labor market opportunities for the population of TDI clients, it should be traceable in the earnings developments of these similar non-claimants also.

Table 7. Results from regressions based on local non-TDI populations. Effects on average earnings next five years (NOK) (standard errors in parenthesis)

\begin{tabular}{lcc} 
& $\begin{array}{c}\text { Matched sample of local non- } \\
\text { clients }\end{array}$ & $\begin{array}{c}\text { Matched sample of ordinary un- } \\
\text { employed }\end{array}$ \\
\cline { 2 - 3 } VR1-intensity & $-3,069^{* *}$ & 1,456 \\
& $(1,315)$ & $(1,933)$ \\
VR2-intensity & $-1,288$ & $3,933^{* *}$ \\
VR3-intensity & $(1,078)$ & $(1,572)$ \\
VR4-intensity & 1,329 & 2,236 \\
& $(1,333)$ & $(1,768)$ \\
PDI-intensity & -215 & $-1,793$ \\
N & $(738)$ & $(1,109)$ \\
\hline
\end{tabular}

Notes: VR and PDI intensities are normalized such that a unit difference corresponds to the average difference (taken over all 10 years) between the two local administrations using the respective strategies least and most. All outcomes are measured in NOK and inflated to the 2013 price level. Reduced sample sizes reflect missing matches of sufficient quality. List of additional control variables used in all the regressions is provided in the Appendix. The reported standard errors are robust, clustered on social insurance districts. $\left.{ }^{* * *}\right)(* * *)$ Significant at the $10(5)(1) \%$ level.

The second group is a matched population of regular unemployed who registered at the same employment offices during exactly the same time period as our TDItics Norway.

${ }^{12}$ For this purpose, we use additional complete population data, made available to us by Statis- 
clients. We use the same matching criteria as for local non-clients. ${ }^{13}$ Note also that this latter population may not be a clean placebo group, since ordinary unemployed job seekers are clients at the same employment offices as the VR-participants, and, hence, may be subject to similar caseworker strategies and also share some of the same (perhaps limited) program resources.

The results from these exercises are shown in Table 7 . For the matched group of non-clients, there is little evidence that future labor market performance is correlated to the local treatment environment. A notable exception is that high local VR1-propensity seems to correlate negatively with future labor earnings. Taken at face value, this may indicate that VR1 is disproportionally used in economic environments with particularly poor employment outlooks for persons with characteristics corresponding to the TDIpopulation. This is the opposite of what we would worry about if we were concerned that the positive impact identified for TDI-claimants was spurious. Turning to unemployed job seekers, we see that future labor earnings correlate positively with the use of sheltered employment (VR2) for TDI-clients, and also with the tendency to grant TDIclients permanent disability insurance without ever referring them to vocational programs. Since both these policies typically imply that the employment offices need to spend less time and energy on TDI-claimants, their apparently positive impacts on ordinary unemployed can probably be explained by more resources becoming available for this group of clients. In any case, the significant coefficients again go in the opposite direction of what we would worry about if we were concerned that our main results were spuriously related to unobserved local labor market fluctuations.

\footnotetext{
${ }^{13}$ Since the population of unemployed is much smaller than the population of non-clients, we lose some observations in this exercise; see Table 7.
} 


\section{Conclusion}

Based on longitudinal administrative register data from Norway, we have exploited local variations in vocational rehabilitation (VR) strategies to identify and estimate the effects of these strategies on temporary disability insurance (TDI) claimants' future employment and earnings performance. We find that VR strategies starting out quickly with placement in the regular labor market tend to be most successful. They raise the employment propensity after the TDI spell, and also entail significant labor earnings gains during the treatment period itself. We also find evidence that strategies focusing on rapid transitions to regular education are successful in terms of raising post treatment earnings and reducing the risk of admission to the permanent disability insurance (PDI) program. However, these programs also involve high short- and medium term costs, in the form of long participation periods with high transfer earnings and low labor earnings. VR strategies focusing on sheltered employment and/or targeted vocational training courses appear to be less successful.

Taken together, our findings give support to the idea that vocational rehabilitation attempts should give high priority to early placement in the regular labor market. In line with recent findings from the U.S. based on randomized controlled trials (Skinner et al., 2009; Campbell et al., 2011), our results indicate that the place-and-train-strategy is more successful in terms of encouraging self-sufficiency and regular employment than the competing train-and-place strategy. This does of course not imply that the other strategies should not have any role to play. What we can say, however, is that within the range of observed local priority variations, we can expect significant gains from giving lower priority to training courses and employment in sheltered firms, and higher priority to subsidized employment in regular firms. 
We also find that local "strictness" with respect to allowing claimants to enter the permanent disability program without having tried vocational rehabilitation first, has a significant negative effect on the probability that TDI spells end with a transition to permanent disability and a positive effect on the probability that they end with employment. The latter effect is much smaller than the former, however, suggesting that a stricter PDI admittance-practice also pushes many claimants over to alternative social insurance programs, such as unemployment insurance or social assistance.

\section{Appendix}

List of and definition of explanatory variables used in the statistical analysis $\left(\mathbf{x}_{\mathbf{i}}\right)$

\begin{tabular}{|c|c|c|}
\hline Variable Content & $\begin{array}{l}\text { Number } \\
\text { of varia- } \\
\text { bles }\end{array}$ & Definition \\
\hline \multicolumn{3}{|l|}{$\begin{array}{l}\text { Individual char- } \\
\text { acteristics }\end{array}$} \\
\hline Age & 40 & One dummy variable for each age $18,19, \ldots, 57$ \\
\hline Sex & 1 & \\
\hline Education & 19 & One dummy variable for each of 19 education level and type combinations \\
\hline Nationality & 4 & $\begin{array}{l}\text { One dummy for each of four immigrant categories, depending on origin country } \\
\text { (Europe/North-America, Africa, Asia, South-America) }\end{array}$ \\
\hline $\begin{array}{l}\text { Previous labor } \\
\text { earnings }\end{array}$ & 13 & $\begin{array}{l}\text { Based on residuals from a regression with sum of last three years labor earnings on } \\
\text { the left hand side of the equation, and age dummies and a sex dummy on the right } \\
\text { hand side. The distribution of residuals is then divided into } 13 \text { categories. }\end{array}$ \\
\hline $\begin{array}{l}\text { Previous social } \\
\text { insurance earn- } \\
\text { ings }\end{array}$ & 12 & $\begin{array}{l}\text { Based on residuals from a regression with sum of last three years social insurance } \\
\text { earnings on the left hand side of the equation, and age dummies and a sex dummy on } \\
\text { the right hand side. The distribution of residuals is then divided into } 12 \text { categories. }\end{array}$ \\
\hline \multicolumn{3}{|l|}{ Time } \\
\hline $\begin{array}{l}\text { Month of entry to } \\
\text { TDI }\end{array}$ & 115 & One dummy for each entry month occurring in the dataset \\
\hline $\begin{array}{l}\text { Local } \\
\text { sosioeconomic } \\
\text { factors }\end{array}$ & 8 & $\begin{array}{l}\text { Age-and-sex-adjusted rates of i) disability, ii) mortality, iii) annual income, and iv) } \\
\text { years of education are computed at both the municipality level and at the level of } \\
\text { employment office districts. All } 9 \text { indicators are added to all regression }\end{array}$ \\
\hline $\begin{array}{l}\text { Local business } \\
\text { cycles }\end{array}$ & 44 & $\begin{array}{l}\text { Three business cycle indicators are computed at the travel-to-work area level ( } 40 \\
\text { regions in Norway). Two indicators are computed for the } 12 \text { month period surround- } \\
\text { ing the month of entry (from } 5 \text { months before to six months after), as well as for the } \\
\text { corresponding period exactly one year after and two years after. These are: i) the } \\
\text { average unemployment rate, ii) the average job finding rate (the number of regis- } \\
\text { tered unemployed in one month that are recorded to have found work in the subse- } \\
\text { quent month). The third indicator is computed on an annual basis, for the of entry } \\
\text { and for the first year after entry. This is: iii) the average job destruction rate (the } \\
\text { number of employees at the start of the year who register as unemployed during the } \\
\text { year), computed separately for } 19 \text { different education levels/types. }\end{array}$ \\
\hline
\end{tabular}




\section{References}

Aakvik, A., Heckman, J., and Vytlacil, E. (2005) Estimating Treatment Effects for Discrete Outcomes when Responses to Treatment Vary: An Application to Norwegian Vocational Rehabilitation Programs. Journal of Econometrics, Vol. 125, $15-51$.

Bound, J. (1989). The Health and Earnings of Rejected Disability Insurance Applicants. American Economic Review, Vol. 79, No. 3, 482-503.

Bratsberg, B., Fevang, E., and Røed, K. (2013) Job Loss and Disability Insurance. Labour Economics, Vol. 24, 137-150.

Burkhauser, R. V. and Daly, M. C. (2011) The Declining Work and Welfare of People with Disabilities: What Went Wrong and a Strategy for Change. AEI Press, Washington D.C.

Burns, T Catty, J, Becker, T., Drake R. E., Fioritti, A., Knapp, M., Lauber, C., Rössler, W, Tomov, T., van Busschbach, J., White, S., and Wiersma, D. (2007) The Effectiveness of Supported Employment for People with Severe Mental illness: A Randomised Controlled Trial. The Lancet, Vol. 370, Issue 9593, 1146-1152

Campbell, K., Bond, G. R., and Drake, R. E. (2011) Who Benefits From Supported Employment: A Meta-analytic Study. Schizophrenia Bulletin, Vol. 37, No. 2, 370-380.

Card, D., Kluve, J., and Weber, A. (2010) Active Labour Market Policy Evaluations: A Meta-analysis. The Economic Journal, Vol. 120, F452-F477.

Catty, J, Becker, T., Drake R. E., Fioritti, A., Knapp, M., Lauber, C., Tomov, T., van Busschbach, J., and Burns, T. (2008) Predictors of Employment for People with Severe Mental Illness: Results of an International Six-Centre Randomised Con- 
trolled Trial. The British Journal of Psychiatry, Vol. 192, 224-231.

Doyle, J. (2008) Child Protection and Adult Crime: Using Investigator Assignment to Estimate Causal Effects of Foster Care. Journal of Political Economy, Vol. 116, 746-770.

Duggan, M. (2005) Do New Prescription Drugs Pay for Themselves? The Case of Second Generation Antipsychotics. Journal of Health Economics, Vol. 24, 1-31.

Duggan, M. and Imberman, S. (2006) Why Are Disability Rolls Skyrocketing? In D. Cutler and D. Wise (eds.): Health in Older Ages: The Causes and Consequences of Declining Disability among the Elderly. University of Chicago Press.

Fevang, E., Hardoy, I., and Røed, K. (2013) Getting Disabled Workers Back to Work: How Important Are Economic Incentives? IZA Discussion Paper No. 7137.

French, E. and Song, J. (2009) The Effect of Disability Insurance Receipt on Labor Supply. Working Paper, Federal reserve Bank of Chicago.

Frölich, M., Hesmati, A., and Lechner, M. (2004) A Microeconomic Evaluation of Rehabilitation of Long-term Sickness in Sweden. Journal of Applied Econometrics, Vol. 19, 375-396.

Howard L. M., Heslin, M, Leese, M., McCrone, P., Rice, C., Jarrett, M., and Spokes, T. (2010) Supported Employment: Randomised Cotrolled Trial. The British Journal of Psychiatry, Vol. 196, 404-4011.

Kluve, J., Card, D., Fertig, M., Góra, M., Jacobi, J., Jensen, P., Leetmaa, R., Nima, L., Patacchini, E., Schaffner, S., Schmid, C. M., van der Klaauw, B., and Weber, A. (2007) Active Labor Market Policies in Europe - Performance and Perspectives. Springer-Verlag Berlin and Heidelberg GmbH \& Co.

Maestas, N., Mullen, K. and Strand, A. (2011) Does Disability Insurance Receipt Dis- 
courage Work? Using Examiner Assignments to Estimate Causal Effects of SSDI Receipt. Rand Working Paper, WR-853-2,

Markussen, S., Mykletun, A., and Røed, K. (2012) The Case for Presenteeism, Journal of Public Economics, Vol. 96, 959-972.

NOU (2012) Arbeidsrettede Tiltak. Norges Offentlige Utredninger No. 2012:6. Oslo.

OECD (2008) OECD Employment Outlook 2008, OECD, Paris.

OECD (2010) Sickness, Disability and Work - Breaking the Barriers. A Synthesis of Findings across OECD Countries. OECD, Paris.

Proba (2012) Bruk av opplæringstiltak for personer med nedsatt arbeidsevne. Forprosjekt til effektevaluering. Rapport 2012:11.

Skinner, R. J.., Bond, G., and Goldman, H. (2009) Social Security and Mental Illness: Reducing Disability with Supported Employment. Health Affairs, Vol. 28, No. 3, 761-770.

Von Wachter, T., Song, J., and Manchester, J. (2011) Trends in Employment and Earnings of Allowed and Rejected Applicants to the Social Security Disability Insurance Pro-gram. American Economic Review, Vol. 101, No. 7, 3308-29.

Waddel, G. (2004) The Back Pain Revolution (Second Edition). Elsevier Health Sciences.

Waddell, G. and Burton A. K. (2006). Is Work Good for Your Health and Well-being? Report for Department for Work and Pensions. TSO (The Stationery Office), London. 